LEADING ARTICLE

\title{
From comic relief to real understanding; how intestinal gas causes symptoms
}

\section{E M M Quigley}

Gut 2003;52:1659-1661

Gas content and transit appear to conspire with the motor and sensory responses of the gut to produce gas related symptoms, both in normal individuals and especially in patients with irritable bowel syndrome (IBS). In relation to gas in IBS, two questions need to be addressed: do IBS patients produce more gas and what are the relationships between intestinal gas and symptoms? The balance of evidence seems to indicate that distension is a real phenomenon in IBS and that such distension accurately reflects gas content. More problematic is extrapolation of the observations relating symptoms to gas transit and retention.

Correspondence to:

Dr E M M Quigley

Department of Medicine,

Clinical Sciences Building,

Cork University Hospital,

Cork, Ireland;

e.quigley@ucc.ie

Accepted for publication 23 July 2003
$\mathrm{P}$ atients with a variety of functional gastrointestinal symptoms commonly ascribe many of their varied and often distressing symptoms to "gas", firmly convinced that an excess of "gas" or "wind" is the root cause of their belching, postprandial fullness, bloating, distension, or flatulence. By the time they seek help from the gastroenterologist, many will have attempted radical dietary adjustments, as well as all that the health food store and high street pharmacy have to offer, to relieve or eradicate "gas".

These symptoms are especially prominent among those who suffer from irritable bowel syndrome (IBS), for whom bloating, distension, and flatulence are significant and sometimes overriding concerns. Long the sole preserve of the music hall and the stand up comedian, the application of serious science to the area of intestinal gas has been long overdue. It is also regrettable that these symptoms have tended to be trivialised and dismissed as imaginary by the medical practitioner; recent studies of relationships between symptoms and quality of life in IBS attest not only to the high prevalence of these symptoms but also to the real distress associated in this disorder with bloating and distension, for example. ${ }^{1-7}$ Indeed, patients will often report that they can cope with pain but cannot tolerate bloating and distension! The distressed patient and the concerned physician can now take heart; gas is being taken seriously!

In relation to the issue of gas in IBS, two separate although interrelated questions need to be addressed: firstly, do IBS patients produce more gas and, secondly, what are the relationships between intestinal gas and symptoms? The answers to these questions should allow us not only to indulge in rational and informed conversations with our patients but also to design and develop therapies that have the potential to alleviate these symptoms.

\section{GAS PRODUCTION}

The first of these is most easily answered. In one of a series of classic studies, ${ }^{8-13}$ Levitt et al, using an argon washout technique, failed to define any increase in endogenous gas production in a group of individuals who nowadays would most likely be classified as IBS; ${ }^{13}$ this was recently confirmed by Serra et al in a group of 20 IBS subjects using the labelled $0.5 \%$ sulphur hexafluoride technique. ${ }^{14}$ It should be noted that others have in contrast reported an increase in colonic fermentation in IBS, ${ }^{15}{ }^{16}$ an issue that remains unresolved and deserving of further study.

\section{GAS CONTENT}

If total gas content is not increased in IBS how then can these patients develop such distressing "gas related" symptoms? The studies from Levitt and his group, in the 1970s, so convincingly debunking the concept of excess gas in IBS, ${ }^{13}$ may have inadvertently contributed to the common tenet that distension and related symptoms were imagined. The clinician was reinforced further in this opinion every time that a distressed female who insisted that she felt "three months pregnant" by the end of the day was, hey presto!, found to have a scaphoid and non-tympanitic abdomen when the great hands were laid. Prefacing his comments with a reassuring "well dearie", the learned man then proceeded to explain the phantom pregnancy in terms of "curvature of the spine", "all in the head", and "weak abdominals". More recently, some doubts began to creep in with the publication of a number of studies employing disparate methodologies suggesting that distension was not only real but also dynamic and subject to significant diurnal variation. ${ }^{17-19}$ Koide et al, using plain abdominal radiographs, suggested that intestinal gas was increased in IBS. ${ }^{18}$ Maxton et al noted a non-significant trend in the same direction based on their computed tomography derived measurements ${ }^{17}$ and that distension could not be explained by voluntary abdominal protrusion, diaphragmatic movement, or lumbar lordosis but appeared to be due to a real increase in the lateral dimensions of the abdominal

Abbreviations: IBS, irritable bowel syndrome 
cavity. ${ }^{17}$ Even the least reproducible of these methods, direct measurement of abdominal girth, demonstrated a progressive increase during the day. ${ }^{17}$ Lewis et al and Lea et al, using applied potential tomography, have confirmed and extended these observations. ${ }^{19} 20$ Their studies revealed considerable fluctuations in abdominal girth over a 24 hour period; girth increased following meal ingestion and was lowest during sleep. ${ }^{19}{ }^{20}$ Interestingly, they and others ${ }^{18}$ recorded a poor correlation between measured distension and symptoms.

\section{"Changes in gas content or volume do not necessarily imply an increase in gas production and could arise within the intestine as a result of altered transit and/or expulsion"}

A new concept emerges from these observations: changes in gas content or volume do not necessarily imply an increase in gas production and could arise within the intestine as a result of altered transit and/or expulsion, without any change in endogenous production; the patient's much derided description of "trapped gas" may, after all, owe more to physiology than imagination!

\section{GAS TRANSIT}

The next step in the resolution of this equation was to explain how gas transit through either the entire intestine, or a part thereof, could be altered to produce regional distension. For this we turn to the pioneering work of the Barcelona group on the handling of gas by the intestine. ${ }^{1421-25}$ While most normal individuals can evacuate even relatively large volumes of gas from the rectum, almost as rapidly as they are infused into the proximal small bowel, the minority who prove to be "gas retainers" are much more likely to experience symptoms, such as pressure, bloating, cramp, or colic, and to register an increase in abdominal girth. ${ }^{21}$ Furthermore, similar infusion rates resulted in gas retention, symptoms, and an increase in abdominal girth in almost all IBS patients. ${ }^{1424}$ What is the mechanism of this retention? Voluntary rectal retention is not a major factor. ${ }^{14}$ The Barcelona group contends instead that gas retention reflects impaired transit and thus a selective form of motor dysfunction, a concept supported by reports from the same group who demonstrated that retention could be exacerbated by both intravenous glucagon ${ }^{23}$ and intraduodenal lipid, ${ }^{24} 25$ potent inhibitors of intestinal motility and tone, and reversed by administration of a prokinetic agent. ${ }^{22}$ The nature of the motor abnormality which results in abnormal gas transit in IBS remains unclear; limited observations in relation to gas infusion in particular ${ }^{26}$ as well as in IBS in general suggest that disturbances in phasic contractions or phasic contractile patterns are unlikely. ${ }^{27-29}$

\section{"The location of gas retention may have an important bearing on the response to gas infusion"}

In the latest study from the Barcelona group, reported in this issue of Gut, Harder and colleagues ${ }^{30}$ now suggest that the location of gas retention may have an important bearing on the response to gas infusion [see page 1708]. Among these normal volunteers, intrajejunal gas infusion was more likely to produce abdominal symptoms than rectal infusion of a similar volume, despite the fact that both infusions produced almost identical changes in abdominal girth. Subsequent scintigraphic studies revealed striking but unsurprising differences in distribution; following intrajejunal infusions, gas was located predominantly in the small intestine, following intrarectal, in the left colon. They also noted different tonic responses to gas in these organs. Gas infusion into the jejunum increased duodenal tone whereas intrarectal infusion produced a profound and sustained relaxation of the rectum, suggesting that intrinsic biomechanical and physiological properties of these organs may largely determine their ability to cope with gas loads.

\section{GAS PERCEPTION}

Impaired transit alone cannot however explain gas related symptoms. A divergence between measured distension on the one hand and symptoms on the other has been a consistent feature of this and other studies. ${ }^{19} 240$ In the glucagon experiments, visible distension was asymptomatic, ${ }^{23}$ yet in the same study a similar degree of retention and distension induced by voluntary suppression of gas evacuation resulted in an increase in symptoms. Similarly, gas retention exacerbated in IBS subjects by intraduodenal lipid infusion led to an increase in abdominal girth but no change in perception. ${ }^{24}$ Symptoms may well result therefore not from gas retention per se but from the local response to this stimulus; the small intestine contracts with a resultant increase in wall tension, thereby inducing symptoms; the colon relaxes and accommodates. When the small intestine is similarly relaxed by glucagon for example, gas infusion no longer produces symptoms.

\section{"Impaired transit alone cannot however explain gas related symptoms"}

One can only speculate on what may transpire in the IBS patient; could for example the hold up in transit described by others at the ileocolonic junction ${ }^{31}$ result in small intestinal gas retention and thus precipitate bloating?

Reports of disparity between distension and symptoms have also led some to invoke altered perception as another factor that may contribute to gas related distress in IBS. The possibility that IBS subjects might be hypersensitive to or intolerant of physiological volumes of intestinal gas was first noted by Lasser and colleagues ${ }^{13}$ and subsequently confirmed by others. ${ }^{142426}$ These observations serve as yet another example of visceral hypersensitivity in this functional disorder. $^{32}$ There are indeed examples of other physiological phenomena, usually subconscious, leading to symptoms in IBS $^{33}$; could "normal" amounts of gas similarly provoke bloating or discomfort in susceptible individuals?

\section{THE STORY SO FAR}

In summary, gas content and transit appear to conspire with the motor and sensory responses of the gut to produce gas related symptoms, both in normal individuals and especially in IBS patients. Gas retention in the small intestine, an organ poorly prepared for this event, is more likely to cause symptoms, especially in an individual who exhibits visceral hypersensitivity. Are these elegant experimental studies relevant to IBS in general? Certainly the balance of evidence does seem to indicate that distension is a real phenomenon in IBS and that such distension accurately reflects gas content. $^{2034}$ More problematic is extrapolation of the observations relating symptoms to gas transit and retention. The Barcelona group have convinced us that abnormal transit of exogenous gas is a real phenomenon in IBS; ${ }^{24}$ what is in question is whether these levels of gas infusion into the proximal small intestine have any relevance to IBS? Could these additional gas loads occur under non-experimental circumstances in IBS? The suggestion that bacterial overgrowth $^{35}{ }^{36}$ or changes in the bacterial flora ${ }^{37-39}$ may occur in IBS would provide one scenario conducive to local increases in gas content; both proposals remain however highly contentious. ${ }^{340}$ We know little of the relationships between 
aerophagia, the other and more likely source of excess gas, and IBS. ${ }^{41}$ Resolution of this issue must await studies which can simultaneously trace the movement of intrinsic or "normal" gas volumes through the intestine, detect changes in abdominal girth, and record associated symptoms.

\section{REFERENCES}

1 Maxton DG, Morris JA, Whorwell PJ. Ranking of symptoms in the irritable bowel syndrome. BMJ 1989;299:1138.

2 Talley NJ, Zinsmeister AR, Van Dyke C, et al. Epidemiology of colonic symptoms and the irritable bowel syndrome. Gastroenterology 1991;101:927-34.

3 Maxton DG, Whorwell PJ. Abdominal distension in the irritable bowel syndrome: the patient's perspective. Eur J Gastroenterol Hepatol 1992;101:927-34

4 Lembo T, Naliboff B, Munakata J, et al. Symptoms and visceral perception in patients with pain-predominant irritable bowel syndrome. Am J Gastroenterol 1999;94:1320-6

5 Whorwell PJ. The problem of gas in the irritable bowel syndrome. Am J Gastroenterol 2000;95:1618-19.

6 Chang L, Lee OY, Naliboff B, et al. Sensation of bloating and visible abdominal distension in patients with irritable bowel syndrome. Am J Gastroenterol 2001;96:3341-7.

7 Hungin APS, Whorwell PJ, Tack J, et al. The prevalence, patterns and impact of irritable bowel syndrome: an international survey of 40,000 subjects. Aliment Pharmacol Ther 2003; 17:643-50.

8 Levitt MD. Volume and composition of intestinal gas determined by means of an intestinal washout technic. N Engl J Med 1971;284:1394-18.

9 Levitt MD. Volume and composition of human intestinal gas. N Engl J Med 1975;293:524-6.

10 Levitt MD, Lasser RB, Schwartz JS, et al. Studies of a flatulent patient N Engl J Med 1976;295:260-2.

11 Bond JH, Levitt MD. Effect of dietary fibre on intestinal gas production and small bowel transit time in man. Am J Clin Nutr 1978:31:S169-74.

12 Sutalf LO, Levitt MD. Follow-up of a flatulent patient. Dig Dis Sci 1979;24:652-4

13 Lasser RB, Bond JH, Levitt MD. Role of intestinal gas in functional abdominal pain. N Engl J Med 1975;293:524-6

14 Serra J, Azpiroz F, Malagelada J-R. Impaired transit and tolerance of intestinal gas in the irritable bowel syndrome. Gut 2001;48:14-19.

15 Haderstorfer B, Psycholgin D, Whitehead WE, et al. Intestinal gas production from bacterial fermentation of undigested carbohydrate in irritable bowe syndrome. Am J Gastroenterol 1989:84:375-8.

16 King TS, Elia M, Hunter JO. Abnormal colonic fermentation in irritable bowel syndrome. Lancet 1998;352:1187-9.

17 Maxton DG, Martin DF, Whorwell PJ, et al. Abdominal distension in female patients with irritable bowel syndrome: exploration of possible mechanisms. Gut 1991:32:662-4.

18 Koide A, Yamaguchi T, Odaka T, et al. Quantitative analysis of bowel gas using plain abdominal radiographs in patients with irritable bowel syndrome. Am J Gastroenterol 2000;95:1735-41.

19 Lewis MJV, Reilly B, Houghton LA, et al. Ambulatory abdominal wall plethysmography: towards objective assessment of abdominal distension in irritable bowel syndrome. Gut 2001;48:216-20.
20 Lea $\mathbf{R}$, Houghton LA, Reilly B, et al. Is abdominal bloating related to physical distension in patients with irritable bowel syndrome (IBS). Gastroenterology 2003;124:A-14

21 Serra J, Azpiroz F, Malagelada J-R. Intestinal gas dynamics and tolerance in humans. Gastroenterology 1998;115:542-50.

22 Caldarella M, Serra J, Azpiroz F, et al. Prokinetic effects in patients with intestinal gas retention. Gastroenterology 2002;122:1748-55.

23 Serra J, Azpiroz F, Malagelada J-R. Mechanisms of intestinal gas retention in humans: impaired propulsion versus obstructed evacuation. Am J Physio Gastrointest Liver Physiol 2001:44:G138-43.

24 Serra J, Salvioli B, Azpiroz F, et al. Lipid-induced intestinal gas retention in irritable bowel syndrome. Gastroenterology 2002;123:700-6.

25 Serra J, Azpiroz F, Malagelada JR. Gastric distension and duodenal lipid infusion modulate intestinal gas transit in humans. Am J Gastroenterol 2002;97:2225-30.

26 Galati JS, McKee DP, Quigley EMM. The response to intraluminal gas in the irritable bowel syndrome: motility versus perception. Dig Dis Sci 1995:40:1381-7.

27 McKee DP, Quigley EMM. Intestinal motility in irritable bowel syndrome: Is IBS a motility disorder? Part 1: Definition of IBS and colonic motility. Dig Dis Sci 1993;38:1761-72

28 McKee DP, Quigley EMM. Intestinal motility in irritable bowel syndrome: Is IBS a motility disorder? Part 2: Motility of the small bowel, esophagus, stomach and gall bladder. Dig Dis Sci 1993;38:1763-82.

29 Quigley EMM. Disturbances in small bowel motility. Baillieres Best Pract Res ClinGastroenterol 1999;13:385-95.

30 Harder H, Serra J, Azpiroz F, et al. Intestinal gas distribution determines abdominal symptoms. Gut 2003:52:1708-13.

31 Trotman IF, Price CC. Bloated irritable bowel syndrome defined by dynamic ${ }^{99 \mathrm{~m} T c}$ bran scan. Lancet 1986;2:364-6

32 Camilleri M, Coulie B, Tack JF. Visceral hypersensitivity: facts, speculations and challenges. Gut 2001;48:125-31.

33 Kellow JE, Eckersley GM, Jones MR. Enhanced perception of physiological intestinal motility in the irritable bowel syndrome. Gastroenterology 1991;101:1621-7.

34 Quigley EMM. The role of gas in IBS. In: Camilleri M, Spiller RC, eds. Irritable bowel syndrome. Diagnosis and treatment. Philadelphia: WB Saunders Co, 2002:77-84.

35 Pimentel M, Chow EJ, Lin HC. Eradication of small bowel bacterial overgrowth reduces symptoms of irritable bowel syndrome. Am J Gastroenterol 2000;95:3503-6.

36 Pimentel M, Chow EJ, Lin HC. Normalisation of lactulose breath testing correlates with symptom improvement in irritable bowel syndrome. A doubleblind, randomised, placebo controlled study. Am J Gastroenterol 2003;98:412-19.

37 Balsari A Ceccarelli A, Dubini F et al. The fecal microbial population in the irritable bowel syndrome. Microbiology 1982;5:185-94.

38 Wyatt GM, Bayliss CE, Lakey AF, et al. The fecal flora of two patients with food-related irritable bowel syndrome during challenge with symptomprovoking foods. J Med Microbiol 1988:26:295-9.

39 Nobaek S, Johansson M-L, Molin G, et al. Alteration of intestinal microflora is associated with reduction in abdominal bloating and pain in patients with irritable bowel syndrome. Am J Gastroenterol 2000;95:1231-8.

40 O'Leary C, Quigley EMM. Small bowel bacterial overgrowth, celiac disease, and IBS: what are the associations? Am J Gastroenterol 2003;98:720-2.

41 Quigley EMM. Aerophagia and intestinal gas. Curr Treat Options Gastroenterol 2002;5:259-65. 